\title{
O PROCESSO DE (DES)NATURALIZAÇÃO DAS PRÁTICAS PUNITIVAS A PARTIR DA PROMULGAÇÃO DO ESTATUTO DA CRIANÇA E DO ADOLESCENTE E DA LEI 13.010/2014
}

\author{
Rebeca Valadão Bussinger ${ }^{1}$ \\ https://orcid.org/0000-0002-8244-3598 \\ Roberta Scaramussa da Silva² \\ https://orcid.org/0000-0001-5472-0036 \\ Bruna de Almeida Costa ${ }^{3}$ \\ https://orcid.org/0000-0001-8430-5730
}

RESUMO: O estudo apresenta uma revisão sistemática de literatura, cujo objetivo foi analisar os processos históricos de (des)naturalização da violência física contra crianças e adolescentes no âmbito familiar contextualizando tais práticas com o advento do ECA (Estatuto da Criança e do Adolescente), promulgado em 1990 e da Lei 13.010/2014. Foram selecionados vinte artigos da base de dados Scielo que foram analisados tendo como referência a análise de conteúdo temático-categorial. Os resultados apontaram que o ECA e a Lei 13.010/2014 são importantes dispositivos de desnaturalização dessa violência, contudo, o enfrentamento de tal realidade ainda permanece como um desafio para as políticas públicas de saúde, educação e assistência social. Observou-se que o castigo físico naturalizado ao longo da história como prática educativa legitimada na família ainda opera e resiste a novos modelos educacionais.

PALAVRAS-CHAVE: violência infantil, maus-tratos, punição corporal.

\section{THE PROCESS OF NATURALIZATION OF PUNITIVE PRACTICES FROM THE PROMULGATION OS THE CHILD AND ADOLESCENT STATUTE AND LAW 13.010/2014}

ABSTRACT: The study presents a systematic literature review, which aimed to analyze the historical processes of (de) naturalization of physical violence

\footnotetext{
${ }^{1}$ Doutora em Psicologia, docente, Universidade Federal do Sul da Bahia, Teixeira de Freitas, Bahia, Brasil, rebeca.bussinger@ufsb.edu.br

${ }^{2}$ Mestre em Psicologia, docente, Universidade Federal do Sul da Bahia, Teixeira de Freitas, Bahia, Brasil, robertascaramussa@ufsb.edu.br

${ }^{3}$ Discente do Curso de Psicologia da Universidade Federal do Sul da Bahia, Teixeira de Freitas, Bahia, Brasil, b.dealmeida39@gmail.com
} 
against children and adolescents in the family context, contextualizing such practices with the advent of the ECA (Statute of the Child and Adolescent), promulgated in 1990 and Law 13.010 / 2014. Twenty articles from the Scielo database were selected and analyzed with reference to thematic-categorical content analysis. The results showed that the ECA and Law 13.010/2014 are important devices to denaturalize this violence, however, facing this reality still remains a challenge for public health, education and social assistance policies. It has been observed that naturalized physical punishment throughout history as a legitimate educational practice in the family still operates and resists new educational models.

KEYWORDS: childhood violence, mistreatment, corporal punishment.

\section{EL PROCESO DE NATURALIZACIÓN DE LAS PRÁCTICAS PUNITIVAS DESDE LA PROMULGACIÓN DEL ESTATUTO DEL NIÑO Y DEL ADOLESCENTE Y LA LEY 13.010/2014}

RESUMEN: El estudio presenta una revisión sistemática de la literatura, cuyo objetivo fue analizar los procesos históricos de (des) naturalización de la violencia física contra niños y adolescentes en el contexto familiar, contextualizando dichas prácticas con la llegada del ECA (Estatuto del Niño y del Adolescente), promulgado en 1990 y la Ley 13.010 / 2014. Veinte artículos de la base de datos Scielo fueron seleccionados y analizados con referencia al análisis de contenido temático-categórico. Los resultados mostraron que el ECA y la Ley 13.010/2014 son dispositivos importantes para desnaturalizar esta violencia, sin embargo, enfrentar esta realidad sigue siendo un desafío para las políticas de salud pública, educación y asistencia social. Se ha observado que el castigo físico natural a lo largo de la historia como una práctica educativa legítima en la familia todavía opera y resiste nuevos modelos educativos.

PALABRAS CLAVE: violencia infantil, maltratamiento, castigo corporal.

\section{Introdução: a infância no Brasil}

Para compreender o processo de (des)naturalização das práticas punitivas ao longo da história é necessária a análise dos percursos que constituíram o modo como a infância foi tratada no Brasil.

Costa (2004) conceitua a ideia da posição puramente instrumental ocupada pelo filho durante o período colonial. A criança embora não fosse tratada como utensílio ou coisa, tal como o escravo, ocupava uma posição 
secundária, logo, não era lida como ator principal da atividade familiar. Durante esse período, o sentido da vida da criança centrava-se em duas representações: social e religiosa. "Os papéis culturais de filho incapaz e de anjinho sobrepunham-se e obscureciam sua condição de etapa biológico-moral no desenvolvimento do adulto." (COSTA, 2004, p. 162). Para o autor esse modo de olhar para a criança, como um ser indigno de atenção, como sujeito em papel secundário e desimportante, promovia pouca ligação entre o adulto e a criança, sendo essa, simplesmente ligada às ideias de propriedade e da religião, que as colocava como anjos. O modo como se entendia a criança no passado, difere muito da ideia contemporânea de infância e sua importância, noções que foram historicamente e socialmente construídas por meio de diferentes dispositivos.

Freitas (2006) aponta uma revalorização da infância através do advento da República, visto que este processo desencadeou a reiteração da imagem da criança como herdeira do novo regime que se instalava. A criança, numa sociedade em permanente projeção para o futuro, facilmente tornou-se componente descritivo de um complexo social no qual o estar-em-formação misturava-se a um estar-em-construção com o qual a "personalidade" do país tornava-se o objeto de reflexão (FREITAS, 2006, p. 252).

Outros processos históricos corroboraram para a revalorização da infância e a construção de uma nova visão acerca da mesma, como as políticas higienistas apontadas por Costa (2004) como precursoras da ideia de nocividade do meio familiar. $\mathrm{O}$ autor apresenta como os higienistas buscaram razões que melhor explicassem a irresponsabilidade até então, generalizada no trato com as crianças, e como apontaram o afrouxamento dos laços afetivos entre pais e filhos como uma das possíveis causas.

Em extenso trabalho sobre o tema, José Maria Teixeira (apud COSTA, 2004 , p. 164) pontuava duas grandes causas de ordem social que determinavam a alta mortalidade infantil: a ilegitimidade dos nascimentos e a falta de educação física, moral e intelectual das mães. Ambas revelavam a omissão, ignorância e descuido dos pais quanto ao destino da prole. Esta ideia de nocividade do meio familiar, justificada pelo alto índice de mortalidade infantil, dentre outros comportamentos que influenciaram no desenvolvimento da criança e impactaram negativamente na ordem social, foi tomada, como o grande trunfo médico na luta pela hegemonia educativa das crianças.

Dentro dessa perspectiva de construção histórica e transformações a respeito do conceito de infância, Leite (2006) pontua como algumas áreas de conhecimento ocupam-se da infância, como a psicologia, a biologia, a 
psicanálise e a pedagogia, buscando respostas para a questão do que seria a infância e, a partir de elaborações dessas esferas do saber, diferentes concepções de infância tomaram forma, tal qual a ideia da criança enquanto sujeito essencialmente diferente do adulto, a crença da criança como uma tábula rasa onde é possível inscrever qualquer coisa, ou que "seu modo de ser adulto é predeterminado pela sua carga genética" (LEITE, 2006, p. 232). Estes argumentos expõem a diversidade de conceitos que foram construídos no decorrer da história, forjando novas representações da infância e, com elas, novos jeitos de olhar e lidar com esse estágio da vida.

A infância então se torna um conceito que ao longo dos séculos foi representado de diferentes maneiras, ocupando múltiplas posições. $\mathrm{Na}$ contemporaneidade, este estágio do desenvolvimento humano recebe maior atenção, com vasta literatura, onde uma quantidade expressiva de aspectos que envolvem o seu desenvolvimento saudável, seja físico ou mental, são analisados. Dentre os aspectos que receberam maior atenção e são examinados, as práticas punitivas contra as crianças (práticas vistas com naturalidade e não problematizadas no passado) tornaram-se objeto de discussão na contemporaneidade.

Diante dessa perspectiva, Nunes e Sales (2016) apontam o exemplo das diferentes formas de violências contra a criança no seio familiar como injustificáveis, por tratar-se de um indivíduo em condições peculiares de desenvolvimento, que o coloca em posição de extrema dependência dos pais, cuidadores, familiares, da sociedade e do poder público. Acerca dessa temática, Nunes e Sales (2016) relatam que embora a negligência seja o tipo mais comum de maus tratos contra as crianças, outros autores apontam o abuso físico como mais frequente.

Para Longo (2005), a violência física aplicada à criança ao nível do senso comum, geralmente relaciona-se aos atos de disciplinar e punir. Sendo o primeiro, de caráter preventivo, onde a intenção é de submeter à disciplina e fazer obedecer, enquanto o último estaria mais relacionado a castigar e infligir pena, e sua intencionalidade seria punitiva. Longo (2005) pontua como através da literatura podemos observar controvérsias quanto ao que seja um ato disciplinador violento por parte dos pais, e os exemplos variam desde uma mera palmada até o espancamento cruel.

Com o advento do Estatuto da Criança e do Adolescente (ECA), Lei № 8.069 promulgada em 1990, novas formas de pensar a infância e a adolescência foram concebidas. Lemos (2008, p. 98) afirma que o ECA inaugurou uma "nova concepção de direitos e deveres pautados na doutrina de proteção integral". 
Para a autora o Estatuto propõe a construção de um modelo de proteção integral às crianças e aos adolescentes e não se restringe unicamente à atenção após a violação desses direitos, mas com antecipação a essa violação. Assim como o marco histórico da criação do ECA, a Lei da Palmada (Lei 13.010/2014), faz emendas ao Estatuto da Criança e do Adolescente, dando ênfase ao castigo físico como "ação de natureza disciplinar ou punitiva com o uso de força física que resulte em sofrimento ou lesão." (LIMA, 2012, p. 95). Logo, a palmada passa a ser considerada uma violência física. Deste modo, esta pesquisa se propõe a analisar como tem se constituído historicamente o processo de (des) naturalização da punição física infantil no âmbito familiar contextualizando tais práticas com o advento do ECA (Estatuto da Criança e do Adolescente), promulgado em 1990 e da "Lei da Palmada" em 2014.

\section{Metodologia}

Para realização da revisão sistemática de literatura foi definida a base de dados SciELO (Scientific Electronic Library Online), plataforma que no Brasil é uma referência para pesquisadores de diferentes áreas de conhecimento. Os dados foram então coletados a partir do levantamento de artigos científicos publicados em periódicos no SciELO a partir de julho de 1990, ano da promulgação do ECA (Estatuto da Criança e do Adolescente) até março de 2018. A seleção dos artigos científicos teve como critério a inclusão, nos títulos, dos seguintes descritores (completos ou em parte): violência infantil, violência contra a criança, maus tratos à criança e punição corporal, todos com o idioma português. Foram excluídos os artigos que tratavam, especificamente, de outras formas de violência infantil tais como a sexual, psicológica e negligência e artigos publicados antes da década de 1990. Ao final da busca foram selecionados vinte artigos.

Os dados foram sistematizados de acordo com Análise de Conteúdo Temático-Categorial (OLIVEIRA, 2008). Para tanto, foram seguidas as etapas propostas pela autora, a saber: leitura flutuante de todos os artigos selecionados com definição dos primeiros elementos dos textos para exploração, definição de hipóteses, determinação de unidades de registro (UR) referendadas nos objetivos específicos do estudo. Após estas etapas procedemos à identificação da UR nos artigos e definidas as seguintes categorias: A naturalização das práticas punitivas no Brasil, Definições de violência, Efeitos da punição física para a criança, Causas da violência física intrafamiliar contra a criança, Estatuto da Criança e do Adolescente, Lei da Palmada e (des)naturalização das práticas 
punitivas no Brasil, Desafios para a (des)naturalização das práticas punitivas no Brasil. Abaixo, o quadro descritivo dos artigos selecionados:

Quadro 1 - Descrição dos artigos selecionados

\begin{tabular}{|c|c|c|c|c|}
\hline Título & Autores & Periodico & Tipo de Estudo & Ano \\
\hline $\begin{array}{l}\text { Atenção a crianças } \\
\text { e adolescentes } \\
\text { vítimas de } \\
\text { violência } \\
\text { doméstica: análise } \\
\text { de um serviço }\end{array}$ & DESLADES, S. F. & $\begin{array}{l}\text { Cad. de } \\
\text { Saúde } \\
\text { Pública }\end{array}$ & $\begin{array}{c}\text { Estudo quanti- } \\
\text { quali. }\end{array}$ & 1994 \\
\hline $\begin{array}{l}\text { Prevalência de } \\
\text { violência física } \\
\text { relatada contra } \\
\text { crianças em } \\
\text { uma população } \\
\text { de ambulatório } \\
\text { pediátrico. }\end{array}$ & $\begin{array}{c}\text { DAVOLI, A.; } \\
\text { PALHARES, F. A. } \\
\text { B. ; CORREA- } \\
\text { FILHO H.R.;DIAS, } \\
\text { A. L. et al }\end{array}$ & $\begin{array}{l}\text { Cad.de } \\
\text { Saúde } \\
\text { Pública, }\end{array}$ & $\begin{array}{c}\text { Estudo } \\
\text { Transversal, } \\
\text { questionário. }\end{array}$ & 1994 \\
\hline $\begin{array}{c}\text { Violência contra } \\
\text { crianças e } \\
\text { adolescentes: } \\
\text { questão social, } \\
\text { questão de saúde. }\end{array}$ & MINAYO, M. C. S. & $\begin{array}{c}\text { Rev. Bra. de } \\
\text { Saude Mat. } \\
\text { Inf. }\end{array}$ & $\begin{array}{l}\text { Revisão de } \\
\text { Literatura. }\end{array}$ & 2001 \\
\hline $\begin{array}{l}\text { Por que as crianças } \\
\text { são maltratadas? } \\
\text { Explicações para a } \\
\text { prática de maus- } \\
\text { tratos infantis na } \\
\text { literatura. }\end{array}$ & $\begin{array}{c}\text { GOMES, R.; } \\
\text { DESLADES, S. F.; } \\
\text { VEIGA, M. M.; } \\
\text { BHERING, C.; } \\
\text { SANTOS, J. F. C. }\end{array}$ & $\begin{array}{l}\text { Cad.de } \\
\text { Saúde } \\
\text { Pública }\end{array}$ & $\begin{array}{l}\text { Revisao } \\
\text { bibliográfica, } \\
\text { Análise de } \\
\text { Conteúdo. }\end{array}$ & 2002 \\
\hline $\begin{array}{l}\text { O uso de palmadas } \\
\text { e surras como } \\
\text { prática educativa. }\end{array}$ & $\begin{array}{l}\text { WEBER, L. N.D.; } \\
\text { VIEZZER, A. P.; } \\
\text { BRANDENBURG, } \\
\text { O. J. }\end{array}$ & $\begin{array}{l}\text { Estudos de } \\
\text { psicologia }\end{array}$ & $\begin{array}{l}\text { Estudo } \\
\text { quanti-quali, } \\
\text { questionário. }\end{array}$ & 2004 \\
\hline $\begin{array}{l}\text { Ética disciplinar e } \\
\text { punições corporais } \\
\text { na infância. }\end{array}$ & LONGO, C.S. & $\begin{array}{l}\text { Psicologia } \\
\text { USP }\end{array}$ & $\begin{array}{c}\text { Estudo } \\
\text { documental. }\end{array}$ & 2005 \\
\hline
\end{tabular}




\begin{tabular}{|c|c|c|c|c|}
\hline $\begin{array}{c}\text { Dimensões } \\
\text { da violência } \\
\text { contra crianças } \\
\text { e adolescentes, } \\
\text { apreendidas do } \\
\text { discurso } \\
\text { de professoras e } \\
\text { cuidadoras. }\end{array}$ & $\begin{array}{l}\text { GOMES, V. L. O.; } \\
\text { FONSECA, } \\
\text { A. D. da. }\end{array}$ & $\begin{array}{c}\text { Texto } \\
\text { contexto - } \\
\text { enfermagem }\end{array}$ & $\begin{array}{l}\text { Estudo } \\
\text { exploratório- } \\
\text { descritivo, } \\
\text { qualitativo, } \\
\text { entrevista semi- } \\
\text { estruturada. }\end{array}$ & 2005 \\
\hline $\begin{array}{c}\text { Violência } \\
\text { doméstica } \\
\text { contra crianças } \\
\text { e adolescentes: } \\
\text { estudo de um } \\
\text { programa de } \\
\text { intervenção. }\end{array}$ & $\begin{array}{l}\text { BRITO, A. M. M. ; } \\
\text { ZANETTAL, } \\
\text { D. M. T.; } \\
\text { MENDONÇA, R. } \\
\text { C. V. } \\
\text {; BARISONL, S. Z. } \\
\text { P. ANDRADE, V. } \\
\text { A. G. }\end{array}$ & $\begin{array}{l}\text { Ciência } \\
\text { e saúde } \\
\text { coletiva }\end{array}$ & $\begin{array}{l}\text { Estudo } \\
\text { qualitativo, } \\
\text { descritiva, } \\
\text { questionário } \\
\text { estruturado. }\end{array}$ & 2005 \\
\hline $\begin{array}{c}\text { A concepção } \\
\text { de educadores } \\
\text { sobre violência } \\
\text { doméstica e } \\
\text { desempenho } \\
\text { escolar. }\end{array}$ & $\begin{array}{l}\text { PEREIRA, P. C.; } \\
\text { WILLIAMS, L. } \\
\text { C. A. de }\end{array}$ & $\begin{array}{l}\text { Psicologia } \\
\text { Escolar e } \\
\text { Educacional }\end{array}$ & $\begin{array}{c}\text { Estudo } \\
\text { qualitativo, de } \\
\text { campo, entrevista } \\
\text { semi- } \\
\text { Estruturada. }\end{array}$ & 2008 \\
\hline $\begin{array}{c}\text { Perspectiva } \\
\text { dos pais sobre } \\
\text { educação e castigo } \\
\text { físico. }\end{array}$ & $\begin{array}{c}\text { DONOSO, M.T. V.; } \\
\text { RICAS, J. }\end{array}$ & $\begin{array}{l}\text { Revista } \\
\text { de Saúde } \\
\text { Pública }\end{array}$ & $\begin{array}{c}\text { Qualitativa, } \\
\text { campo, } \\
\text { entrevistas semi - } \\
\text { estruturada, } \\
\text { análise do } \\
\text { discurso. }\end{array}$ & 2009 \\
\hline $\begin{array}{l}\text { Maus-tratos } \\
\text { infantis: um } \\
\text { resgate da } \\
\text { história e das } \\
\text { políticas de } \\
\text { proteção. }\end{array}$ & $\begin{array}{l}\text { MARTINS, C. B. } \\
\text { G.de; JORGE, } \\
\text { M. H. P.M.de }\end{array}$ & $\begin{array}{l}\text { Revista de } \\
\text { Saúde } \\
\text { Pública }\end{array}$ & $\begin{array}{c}\text { Revisão } \\
\text { bibliográfica. }\end{array}$ & 2010 \\
\hline $\begin{array}{c}\text { Maus tratos contra } \\
\text { crianças e } \\
\text { Adolescentes. }\end{array}$ & $\begin{array}{c}\text { MARTINS, C. B.G. } \\
\text { de }\end{array}$ & $\begin{array}{c}\text { Revista } \\
\text { Brasileira de } \\
\text { Enfermagem }\end{array}$ & $\begin{array}{c}\text { Revisão } \\
\text { bibliográfica. }\end{array}$ & 2010 \\
\hline
\end{tabular}




\begin{tabular}{|c|c|c|c|c|}
\hline $\begin{array}{c}\text { Reincidência } \\
\text { da violência } \\
\text { contra crianças } \\
\text { no Município de } \\
\text { Curitiba: um olhar } \\
\text { de gênero. }\end{array}$ & $\begin{array}{c}\text { FONSECA, R. M. } \\
\text { G. S.; EGRY, } \\
\text { E. Y.; } \\
\text { NOBREGA, C. } \\
\text { R.;APOSTOLICO; } \\
\text { M. R.; }\end{array}$ & $\begin{array}{l}\text { Acta paulista } \\
\text { enfermagem }\end{array}$ & $\begin{array}{l}\text { Estudo de } \\
\text { abordagem } \\
\text { quantitativa do } \\
\text { tipo descritivo } \\
\text { exploratório. }\end{array}$ & 2012 \\
\hline $\begin{array}{l}\text { Identificação e } \\
\text { Notificação dos } \\
\text { Maus- tratos } \\
\text { Infantis no Setor } \\
\text { Educacional. }\end{array}$ & $\begin{array}{l}\text { BAZON, M. R.; } \\
\text { FALEIRO, J. M. }\end{array}$ & Paidéia & $\begin{array}{l}\text { Analise quanti- } \\
\text { interpretativa, } \\
\text { questionário } \\
\text { com questões } \\
\text { abertas e } \\
\text { fechadas. }\end{array}$ & 2013 \\
\hline $\begin{array}{c}\text { As possibilidades } \\
\text { de enfrentamento } \\
\text { da violência } \\
\text { infantil na consulta } \\
\text { de enfermagem } \\
\text { sistematizada. }\end{array}$ & $\begin{array}{l}\text { APOSTÓLICO, } \\
\text { M.R.; HINO, P.; } \\
\text { EGRY, E.Y. }\end{array}$ & $\begin{array}{c}\text { Revista } \\
\text { escola } \\
\text { enfermagem } \\
\text { USP }\end{array}$ & $\begin{array}{l}\text { Estudo descritivo, } \\
\text { qualitativo, tipo } \\
\text { estudo de caso, } \\
\text { web-questionário. }\end{array}$ & 2013 \\
\hline $\begin{array}{l}\text { Fatores associados } \\
\text { à notificação } \\
\text { de maus-tratos } \\
\text { em crianças e } \\
\text { adolescentes } \\
\text { na atenção básica. }\end{array}$ & $\begin{array}{l}\text { MOREIRA, G. } \\
\text { A. R. }\end{array}$ & $\begin{array}{l}\text { Ciência } \\
\text { e saúde } \\
\text { coletiva }\end{array}$ & $\begin{array}{c}\text { Estudo } \\
\text { transversal, } \\
\text { análises bivariada } \\
\text { e multivariada } \\
\text { por regressão. }\end{array}$ & 2014 \\
\hline $\begin{array}{l}\text { Maus-tratos } \\
\text { à infância: As } \\
\text { referências dos } \\
\text { técnicos das } \\
\text { Comissões de } \\
\text { Proteção de } \\
\text { Crianças e Jovens. }\end{array}$ & $\begin{array}{l}\text { OLIVEIRA, P. S. } \\
\text { de; SIMOES, A. }\end{array}$ & $\begin{array}{c}\text { Revista } \\
\text { Portuguesa } \\
\text { de } \\
\text { Enfermagem } \\
\text { de Saúde } \\
\text { Mental }\end{array}$ & $\begin{array}{l}\text { Estudo com } \\
\text { caráter } \\
\text { exploratório, } \\
\text { descritivo, } \\
\text { pesquisa } \\
\text { quantitativa. }\end{array}$ & 2014 \\
\hline $\begin{array}{l}\text { Caracterização } \\
\text { da violência } \\
\text { doméstica } \\
\text { contra crianças } \\
\text { e adolescentes } \\
\text { e as estratégias } \\
\text { interventivas em } \\
\text { um município do } \\
\text { Estado do Rio de } \\
\text { Janeiro. }\end{array}$ & $\begin{array}{l}\text { PINTO JUNIOR, } \\
\text { A. A.; CASSEPP- } \\
\text { BORGES, V.; } \\
\text { SANTOS, J.G. dos }\end{array}$ & $\begin{array}{l}\text { Cadernos } \\
\text { de saúde } \\
\text { coletiva }\end{array}$ & $\begin{array}{l}\text { Estudo } \\
\text { documental, } \\
\text { análises } \\
\text { descritivas, } \\
\text { quantitativa }\end{array}$ & 2015 \\
\hline
\end{tabular}




\begin{tabular}{|c|c|c|c|c|}
\hline $\begin{array}{c}\text { Enfrentar a } \\
\text { violência infantil } \\
\text { na Atenção } \\
\text { Básica: como } \\
\text { os profissionais } \\
\text { percebem? }\end{array}$ & $\begin{array}{l}\text { EGRY, E. Y., } \\
\text { APOSTÓLICO, M. } \\
\text { R., MORAIS, T. C. } \\
\text { P.,LISBOA, } \\
\text { C. C. R. }\end{array}$ & $\begin{array}{c}\text { Revista } \\
\text { Brasileira de } \\
\text { Enfermagem }\end{array}$ & $\begin{array}{c}\text { Estudo descritivo, } \\
\text { qualitativo, } \\
\text { Tipesc, entrevista } \\
\text { semiestruturada, } \\
\text { análise Alceste. }\end{array}$ & 2017 \\
\hline $\begin{array}{l}\text { Notificação da } \\
\text { violência infantil, } \\
\text { fluxos de atenção } \\
\text { e processo de } \\
\text { trabalho dos } \\
\text { profissionais da } \\
\text { Atenção Primária } \\
\text { em Saúde. }\end{array}$ & $\begin{array}{c}\text { EGRY, E. Y.; } \\
\text { APOSTOLICO, M. } \\
\text { R.; MORAIS, T. } \\
\text { C. P. }\end{array}$ & $\begin{array}{l}\text { Ciência } \\
\text { e saúde } \\
\text { coletiva }\end{array}$ & $\begin{array}{c}\text { Estudo } \\
\text { qualitativo, } \\
\text { descritivo } \\
\text { exploratório, } \\
\text { fundamentado. }\end{array}$ & 2018 \\
\hline
\end{tabular}

Fonte: Elaborado pelas autoras.

\section{Resultados e discussão}

\section{A naturalização das práticas punitivas no Brasil}

Para os autores dos artigos pesquisados a naturalização da violência física infantil com caráter punitivo tem pilares socio-historicamente construídos. Weber, Viezzer e Brandenburg (2004) destacam que essa prática da violência, comum em nossa cultura, é sustentada por ideias transmitidas desde a Antiguidade na forma de provérbios milenares que instruíam os pais a educarem e disciplinar seus filhos com a vara. Isso também é destacado por Minayo (2001) através da explicitação dessa orientação punitiva até mesmo na própria lei, e cita como exemplo a lei hebraica do período de 1250-1224 a.C. que transmitia o direito dos anciãos de punir filhos que desobedecessem aos pais com apedrejamentos ou morte.

Longo (2005) apresenta uma discussão a respeito da permanência dos modos de sociabilidade doméstica no Brasil, pautados pelas práticas punitivas corporais. O castigo físico em crianças foi introduzido no Brasil pelos padres jesuítas, pois a correção era tida como uma forma de amor e a punição corporal era inserida na chamada "Pedagogia do Amor Correcional", que pregava a necessidade de punições corporais para melhor educar as crianças. Ainda no âmbito religioso, Weber, Viezzer e Brandenburg (2004) discutiram teoricamente como as ideias expressas por Santo Agostinho (354-430 d.C), acerca da não existência da inocência infantil, fundamentadas no princípio de que a criança trazia consigo o pecado original ao nascer, provocaram por vários séculos 
uma deturpação da imagem da infância. Partindo desse pressuposto, a "luta contra o pecado" deveria ocorrer através do combate à infância, anulando sua corrupção, com varas e palmatórias.

Também Longo (2005) expõe como a partir do século XX, os livros de orientação a pais e educadores começam a ser publicados de forma massiva. Estes materiais revelaram que, mesmo na atualidade, com a luta pela abolição das punições corporais em crianças, há autores que ainda defendem essas práticas. A respeito destes livros, ainda conforme o mesmo artigo revisado, constatou-se que na literatura recente (1981-2000), há um predomínio do discurso contrário à punição corporal doméstica de crianças no Brasil, no entanto, há autores que ainda se mostram favoráveis a essas práticas e estes possuem grande aceitação junto ao público.

\section{Definições de violência}

As definições de violência contra a criança encontradas nos artigos tiveram duas principais manifestações. A primeira se refere principalmente às práticas educativas pautadas na violência física contra a criança, com caráter punitivo e sem abertura ao diálogo. Nesta definição, a que não deixa sequelas observáveis na criança, tal qual a palmada, é considerada uma violência que carece de discussões e estudos (MARTINS;IORGE, 2010; APOSTÓLICO; HINO; EGRY, 2013; OLIVEIRA,SIMÕES, 2014; EGRY et al., 2017; EGRY; APOSTOLICO; MORAIS, 2018; GOMES; FONSECA, 2005; PEREIRA; WILLIAMS, 2008; BAZON; FALEIRO, 2013; MINAYO, 2001; GOMES, 2002; LONGO, 2005; MARTINS, 2010; DESLANDES, 1994; DAVOLI et al., 1994; BRITO, 2005; MOREIRA et al., 2014; WEBER; VIEZZER; BRANDENBURG, 2004; DONOSO; RICAS, 2009; FONSECA et al. , 2012; PINTO JUNIOR; CASSEPP-BORGES; SANTOS, 2015; GOMES; FONSECA, 2005.). Longo (2005) exemplifica essa concepção, ao pontuar que:

\footnotetext{
[...] a literatura apresenta controvérsias quanto ao que seja um ato disciplinador violento por parte dos pais, podendo variar de uma simples palmadinha no bumbum até o espancamento cruel, embora existam ponderações científicas mais recentes no sentido de que a violência deve se relacionar a qualquer ato disciplinador que atinja o corpo de uma criança ou de um adolescente (LONGO, 2005, p. 102).
}

A segunda definição e a mais encontrada dentre os artigos analisados, trata-se da violência que deixa marcas visíveis no corpo da criança, como o 
espancamento com sequelas mais evidentes. Este tipo de violência foi retratado em dezesseis artigos, em especial aqueles que basearam seus estudos em questionários e entrevistas com profissionais da educação e da saúde, além de dados extraídos de centros de saúde, onde a violência física com sequelas evidentes é mais investigada por sua fácil detecção.

Davoli (1994), retoma a "síndrome da criança espancada" expressão que contribuiu para a identificação do conjunto de sinais encontrados em crianças agredidas, tais como "hematoma subdural, fraturas múltiplas e sem explicações em diferentes estágios de consolidação, falhas no desenvolvimento, edema e/ou hematoma dos tecidos moles (p. 93)".

Donoso e Ricas (2004) trazem a ideia de que:

[...] os limites tolerados de intensidade, frequência e formas do castigo físico educativo culturalmente aceitos são muito variáveis entre grupos sociais e famílias. As simples palmadas coexistem com os espancamentos, sendo justificadas da mesma forma: a necessidade educativa. [...]quando o castigo físico não traz os resultados desejados pelo educador, a tendência é o aumento da intensidade e frequência levando a um círculo vicioso que pode desembocar em situações trágicas (p. 79).

A violência física que provoca marcas visíveis no corpo da criança, proporciona uma identificação mais rápida por outrem e, consequentemente, por sua fácil detecção, mais numerosos serão os dados, análises e discussões promovidos a partir destas denúncias. Isto justifica a violência física que deixa marcas ter maior prevalência dentre os artigos analisados. Essa prevalência também torna possível considerar que os processos de desnaturalização dessa prática estão mais voltados a esse tipo específico de violência física, enquanto outros, considerados "menos severos", por não apresentarem sequelas facilmente detectáveis, são pouco debatidos e, consequentemente, há um número menor de estratégias de intervenção.

\section{Efeitos da punição física para a criança}

Embora todos os artigos pesquisados compreendam os castigos físicos perpetrados no âmbito familiar contra crianças e adolescentes como uma forma de violência, apenas quatro deles trataram especificamente dos efeitos nocivos dela. Pinto-Junior, Cassepp-Borges e Santos (2015) trazem informações acerca dos diversos agravos à saúde física e psicológica das vítimas, como, por exemplo, "distúrbio de humor, ansiedade, problemas de sono, 
dificuldades escolares, distúrbios neurológicos, depressão, perdas significativas e persistentes de qualidade de vida na idade adulta, além da possibilidade de reprodução da violência sofrida" (p. 125).

Donoso e Ricas (2009) constataram como as dificuldades escolares são uma consequência da violência intrafamiliar e, em função disso, apontam que caberia aos profissionais da educação uma maior apropriação desses estudos. Pereira e Williams (2008) ao pesquisarem sobre percepção de docentes de escolas públicas sobre as relações entre violência doméstica e desempenho escolar concluíram que em $91 \%$ das respostas encontradas os professores responderam afirmando há uma relação direta entre violência doméstica e fracasso escolar. Martins e Jorge (2010) em pesquisa bibliográfica realizada sobre o tema apontaram que a violência doméstica tem sido uma das principais causas de mobi-mortalidade de crianças e adolescentes além de destacarem as possíveis sequelas da violência para o crescimento e desenvolvimento das mesmas.

\section{Causas da violência física intrafamiliar contra a criança}

No que diz respeito às principais causas da violência física contra a criança no seio familiar, os artigos demonstraram que este é um problema multicausal, que abrange inúmeros aspectos e as suas principais explicações estão pautadas, principalmente, na naturalização dessa prática (DAVOLI et al., 1994; GOMES, 2002; WEBER; VIEZZER; BRANDERBURG, 2004; LONGO, 2005; DONOSO; RICAS, 2009; FONSECA et al., 2012). Davoli (1994) relata:

No Brasil, a utilização da força física como medida disciplinar é parte integrante dos costumes pedagógicos, transmitidos nas famílias de geração a geração. O limite entre disciplina e violência é definido pelos padrões comunitários de tolerância ao uso da força física contra crianças (DAVOLI, 1994, p. 94).

Esta concepção traz um aspecto importante para a compreensão do fenômeno, que é o caráter geracional dessa prática. Acerca deste aspecto, Fonseca et al. (2012) trazem a seguinte informação: "[...] a violência é também um fenômeno de repetição intergeracional. Dessa forma, adultos que sofreram violência durante a infância tendem a repetir o comportamento com seus próprios filhos, mediado positiva ou negativamente por certos determinantes" (p. 896).

A força física como parte integrante dos costumes pedagógicos não só 
torna mais fácil a sua repetição, em detrimento da possibilidade de se pensar novas práticas educacionais, mas também contribui com o uso de diferentes justificativas para a sua utilização. Donoso e Ricas (2009) apontam que "Alguns entrevistados reconhecem como legítima a prática do castigo físico, frequentemente acrescentando que o comportamento da criança, circunstâncias, motivação ou formas de aplicação podem justificar seu uso" (p. 83).

Weber, Viezzer e Brandenburg (2004) relatam que a falta de conhecimento dos pais sobre as fases do desenvolvimento infantil, os malefícios da educação coercitiva e de outras estratégias educativas também se constituem em importantes causas do fenômeno da naturalização da violência física contra a criança, tal como explicitado no trecho: " [...] a falta de conhecimento dos pais pode produzir sentimentos de incompetência e irritação por não saber como se comportar diante do filho" (p. 229).

As questões socioeconômicas também apareceram como aspectos relacionados ao fenômeno da violência física (DESLANDES, 1994; MINAYO, 2001; BRITO, 2005; PEREIRA; WILLIAMS, 2008; MARTINS, 2010; OLIVEIRA; SIMOES, 2014; PINTO-JUNIOR; CASSEPP-BORGES; SANTOS, 2015). Dentro dessa perspectiva Oliveira e Simões (2014) apontaram que a precariedade socioeconômica, juntamente com outros fatores, como baixa formação escolar, alcoolismo e nível alto de estresse, estariam relacionados à prática da violência física contra a criança, enquanto os maus-tratos emocionais seriam mais característicos dos núcleos socioeconomicamente favorecidos. Pinto-Junior, Cassepp-Borges e Santos (2015) também relacionaram as condições precárias de vida com a possível prática da violência doméstica contra crianças e adolescentes. Em contrapartida a estas afirmações, a autora Guerra (1989), citada por Pereira e Williams (2008), afirmam que "a violência intrafamiliar pode acontecer em qualquer lar, independentemente de cultura e do nível socioeconômico" ( $p$. 147). Importante observação elencada por Minayo (2001), foi acerca da escassez de dados sobre as classes médias e altas. Esta observação torna possível supor que, essa escassez de dados colabora para a hipótese de que as classes mais baixas praticariam mais a violência física contra a criança o que dificulta a análise dessa incidência nas classes mais altas.

Outros fatores desencadeantes da violência, além da questão socioeconômica, também foram apresentados, tais como o alcoolismo, a baixa formação escolar e o nível alto de estresse, conflitos do casal, falta ou excesso de trabalho e fatores socioculturais (BRITO, 2005; OLIVEIRA; SIMOES, 2014). 
Estatuto da Criança e do Adolescente, Lei da Palmada e (des)naturalização das práticas punitivas no Brasil

Esta categoria concentra os artigos que apresentaram a promulgação do ECA e a Lei da Palmada como dispositivos legais encarregados de garantir a proteção integral à criança e ao adolescente. Neste sentido, a maioria dos artigos analisados reconheceram que o Estatuto da Criança e do Adolescente contribui para uma maior visibilidade acerca das questões que envolvem a criança no Brasil, atuando como marco legal e conceitual sobre a forma como a infância deve ser tratada no Brasil. (GOMES; FONSECA, 2005; BRITO, 2005; PEREIRA; WILLIAMS, 2008; MARTINS; JORGE, 2010; MARTINS, 2010; FONSECA et al., 2012; BAZON; FALEIRO, 2013; MOREIRA et al., 2014; PINTO JUNIOR, CASSEPP-BORGES; SANTOS, 2015; EGRY et al., 2017). Contudo, nenhum dos artigos levantando abordou a Lei da Palmada em suas considerações e análises.

Martins e Jorge (2010) relataram como o ECA trouxe avanços no tratamento jurídico "[...] contribuindo para a consolidação da consciência social e entendendo o ECA como um instrumento de garantir ao bem-estar de nossa infância e juventude" (p. 426). Já Pinto-Junior, Cassepp-Borges e Santos (2015) apresentam um contraponto a esta ideia de avanços no que concerne à promulgação do ECA, ao relatar que " [...] embora com a criação de tais leis, estatísticas nacionais e internacionais indicam que a violência doméstica é, ainda, um grave problema em termos de incidência e de prevalência" ( $p$. 125). Constata-se que mesmo após muitos anos desde a promulgação do ECA e da criação de outras leis, como a Lei da Palmada, de 2014, a violência doméstica contra a criança ainda é considerada um problema que persiste na contemporaneidade.

Dos dez artigos que citaram o ECA, quatro deles retratam de forma mais aprofundada a questão da identificação e notificação dos profissionais encarregados de denunciar os casos de violência ao Conselho Tutelar. Moreira et al. (2014, p. 4268) relata como o ECA tornou possível a obrigatoriedade da " [...] notificação pelos profissionais e responsáveis da área da saúde e da educação de casos suspeitos ou confirmados de maus-tratos (art. 13), prevendo pena para a não comunicação dos casos aos órgãos de proteção (art. 245)". O estudo exposto pela autora objetivou analisar os fatores associados à notificação de maus-tratos em crianças e adolescentes na atenção básica, e em seus resultados, foi possível verificar: 
[...] o distanciamento entre identificar maus-tratos em crianças e adolescentes e proceder com a notificação dos casos. A frequência da notificação encontrada $(17,0 \%)$ é baixa, tendo em vista a obrigatoriedade desse ato preconizado pelo ECA e pela Portaria no 104/2011 do Ministério da Saúde (p. 4271).

Este distanciamento entre as concepções propostas pelo ECA e as ações dos profissionais também é retratado por Pereira e Williams (2008) em estudo que teve como objetivo identificar as concepções de profissionais da educação sobre violência doméstica. Foi revelado que o procedimento de comunicação às autoridades preconizado pelo ECA ficou em segundo lugar dentre as respostas apresentadas pelas educadoras entrevistadas, sendo a resposta mais frequente " [...] dar para a criança, na escola, atendimento especial" (p. 148). O estudo considera um procedimento inadequado pois, segundo o artigo, educadores não estão capacitados nem legitimados a intervenções especializadas com crianças, adolescentes e famílias. Entretanto, o trabalho também verificou um dado positivo, que é o fato de as educadoras terem demonstrado estarem atentas à identificação da criança vítima de violência através da observação de marcas, sinais e comportamentos.

\section{Desafios para a (des)naturalização das práticas punitivas no Brasil}

No que se refere aos desafios para a desnaturalização das práticas punitivas contra a criança no Brasil, a resistência das famílias em adotarem novas práticas educacionais foi a mais citada dentre os artigos analisados. Este fato, segundo os autores, é sustentado pela naturalização sócio histórica das práticas punitivas e sua reprodução pelo núcleo familiar (GOMES, FONSECA, 2005; BRITO, 2005; DONOSO; RICAS, 2009; APOSTÓLICO; HINO; EGRY, 2013; LONGO, 2005; EGRY et al., 2017; EGRY; APOSTOLICO; MORAIS, 2018; MINAYO, 2001; GOMES, 2002; PEREIRA; WILLIAMS, 2008; BAZON; FALEIRO, 2013; DAVOLI et al., 1994; PINTO JUNIOR, CASSEPP-BORGES; SANTOS, 2015).

Segundo os autores o castigo físico ainda permanece no imaginário social como um recurso permitido e apropriado para a educação da criança. Esta ferramenta está associada ao modelo cultural que a justifica e reforça o seu uso, provocando, conforme apontada por Apostólico, Hino e Egry (2013), a incorporação da violência doméstica no microssistema familiar como um fenômeno aceitável na perspectiva não só dos pais, como das próprias crianças vítimas das agressões. Longo (2005) também exemplifica essa naturalização enquanto desafio, ao constatar como a punição corporal por ter um efeito 
imediato, se mostra eficaz ao agressor que reforçará o seu comportamento de bater, o que constitui um entrave ao processo de desnaturalização e promoção de novas ferramentas educacionais.

A necessidade de uma maior capacitação dos profissionais envolvidos no ato de identificar e notificar as agressões físicas contra crianças foi uma das ideias mais presentes a respeito dos desafios ao processo de desnaturalização. Duas categorias de profissionais foram as mais tratadas neste quesito: profissionais da saúde e da educação, sendo os primeiros os mais citados. Entretanto, conforme indica Egry et al. (2017), esta necessidade de treinamento e capacitação deve ocorrer nas diversas áreas que atuam com situações de violência, como a justiça, a segurança e o serviço social, para que ocorra uma melhor articulação do trabalho em rede. Acerca dessa capacitação, Egry, Apostólico e Morais (2018) afirmam que é necessária a "[...] compreensão ampliada do fenômeno, incluindo conhecimentos sobre gênero, geração e estratégias diversificadas de reconhecimento e enfrentamento" (p. 90), enfatizando o desafio e a necessidade de construção de redes coordenadas e articuladas com ênfase na prevenção da violência.

Sobre a capacitação dos profissionais do âmbito da saúde, Minayo (2001) relata como esta área tem concentrado seus esforços em atender, apenas, os efeitos da violência, ou seja, os traumas e as lesões físicas nos serviços de emergência, entretanto, para além deste tipo de atendimento, é necessário o estudo dos aspectos psicossociais envolvidos neste fenômeno. Porém, conforme aponta o mesmo artigo, este cenário tem se modificado, mesmo que aos poucos. Outra problemática inserida na capacitação dos profissionais da saúde, conforme aponta Gomes (2002), é a necessidade de desconstrução do reducionismo da temática dos maus-tratos infantis, que são "[...] atravessados por uma complexidade de fatores, não podem ser explicados por um modelo teórico que sugira uma abordagem determinista ou única sobre o problema" (p. 712).

Pereira e Willians (2008) e Bazon e Faleiros (2013) tratam acerca da capacitação dos profissionais da educação. Ambos os estudos evidenciaram a defasagem entre o ideal preconizado pelo ECA no que concerne ao papel dos profissionais do âmbito educacional e as concepções e ações perpetradas por eles. O estudo de Pereira e Willians (2008) revelou que as educadoras entrevistadas, carecem de informações sobre o tema da violência doméstica e como proceder nesses casos, além de um desconhecimento do Estatuto da Criança e do Adolescente. Outro elemento levantado no estudo foi o "temor político" (p. 150), por tratar-se de entrevistas realizadas numa rede municipal de ensi- 
no, no período de campanha dos candidatos à prefeitura. Muitas educadoras sentiram-se inibidas ao responderem o questionário, o que revela o quanto a temática da violência doméstica ainda é considerada um tabu por muitos. Este tabu engloba, de acordo com os autores, o desconforto das educadoras ao notificarem ao Conselho Tutelar as suspeitas de casos de agressão à criança, pelo pensamento culturalmente enraizado de que a família é uma instituição privada, que não deve sofrer interferências externas. Uma importante problemática apontada pelo mesmo artigo foi acerca da desconfiança na eficiência das instituições responsáveis por receber as notificações de maus-tratos, por parte dos profissionais do setor educacional, essa desvalorização pode afetar o bom funcionamento das ferramentas já existentes de combate à violência infantil.

Egry et al. (2017) reitera a necessidade de uma formação qualificada dos profissionais que se depararão com situações de violência infantil, no que se refere aos "[...] processos de trabalho, cuidados e medidas específicas que realizam, para que haja um estímulo das intervenções apropriadas ao momento do ciclo de violência, podendo levar até mesmo a sua interrupção" (p. 124).

Assim, a maioria dos artigos que contemplaram essa categoria retrataram a importância das políticas públicas que podem promover uma ampliação e aprimoramento das estratégias que visam combater estas práticas tão enraizadas no seio familiar. O reconhecimento desta violência como um problema social multifacetado também se constitui enquanto um desafio para a criação de ferramentas de combate.

Embora já existam iniciativas políticas para o enfrentamento dos maus-tratos na infância, os artigos analisados concordaram acerca da importância da intensificação de ações de prevenção, integração de diferentes segmentos sociais, como setores da saúde, educação, assistência social, segurança e justiça, para que possibilitem discussões e reflexões mais amplas entre si. Estratégias preventivas, diagnósticas e terapêuticas, em suma, foram apontadas como carecedoras de intensificação e aprimoramento. Nesse contexto, em Gomes e Fonseca (2005), a academia foi descrita como uma estrutura capaz de promover conhecimentos teóricos e práticos acerca dessa temática, que auxiliarão na implementação de políticas públicas mais eficientes.

Outro importante fator é a necessidade de promoção dos estudos que visem a obtenção de mais dados alicerçados na realidade empírica brasileira. Conforme evidenciado por Gomes (2002), “[...] muito há que se construir para que se afine o foco das políticas públicas que desejam formular princípios para se abordar o assunto em pauta" (p. 713). Ainda a respeito da obtenção de mais dados sobre essa realidade, Davoli et al. (1994) aponta como a aplicação de 
questionários é um importante instrumento de medida quantitativa em uma população, visando futuros estudos de incidência ou prevalência. Pinto-Junior, Cassepp-Borges e Santos (2015) reiteram esta análise, ao afirmar que o preenchimento completo e adequado dos prontuários, favorece uma maior visibilidade do fenômeno pesquisado.

\section{Considerações finais}

A partir destes estudos, foi possível concluir que o Estatuto da Criança e do Adolescente trouxe significativos avanços ao processo de desnaturalização da violência física infantil, principalmente no que concerne ao papel dos profissionais da saúde e da educação ao estarem mais atentos aos sinais de violência física, para posterior notificação ao Conselho Tutelar. O ECA e outros dispositivos jurídicos que visam a defesa da criança vítima de violência, também proporcionaram mais discussões e estudos acerca dessa temática. Essas discussões propiciaram, por exemplo, um maior número de livros de orientação a pais e educadores contrários à punição física na contemporaneidade.

Embora o ECA tenha contribuído para o aumento de notificações de casos de violência contra a criança e, consequentemente, mais investimento em intervenções nessa área, através das políticas públicas, foi possível identificar muitos desafios a esse processo de desnaturalização, tais como a persistência das práticas pedagógicas pautadas na violência devido à crença arraigada em nossa sociedade de que esta é uma prática educacional válida e efetiva, além da concepção amplamente difundida de que a família é uma instituição privada e intocável, onde não se deve intervir, fato que constitui-se em obstáculo para a prática das notificações aos órgãos responsáveis pelo problema.

A violência contra a criança é sustentada por séculos de propagação de discursos que construíram no imaginário social a ideia de que essa é uma prática aceitável e, por vezes, indispensável. Devido à complexidade do fenômeno, por este ser multifacetado, os estudos levantados concordaram e discordaram em diferentes aspectos que abarcam a violência física contra a criança, desde as suas principais causas, efeitos nocivos à criança, até a prevalência ou não em classes sociais mais baixas.

Os estudos também demonstraram que a violência física mais discutida entre os artigos analisados é a que deixa sequelas visíveis na criança, tornando possível verificar como a violência contra a criança é mais problematizada quando ocorre o espancamento. Logo, as palmadas e práticas punitivas que não deixam marcas, são pouco registradas, estudadas e, como consequência, 
há escassa intervenção para esse segundo tipo.

Por fim, a pesquisa identificou a necessidade de englobar diferentes áreas de conhecimento em revisões sistemáticas de literatura futuras. Estudos que abordem a justiça, a segurança, o serviço social, a educação e a saúde devem ser contempladas para uma melhor articulação e compreensão deste processo de (des)naturalização.

\section{Referências}

APOSTOLICO, Maíra Rosa; HINO, Paula; EGRY, Emiko Yoshkawa. As possibilidades de enfrentamento da violência infantil na consulta de enfermagem sistematizada. Rev. esc. enferm. USP, São Paulo, v. 47, n.2, p. 320-327, abr. 2013.

BAZON, Marina Rezende; FALEIROS, Juliana Martins. Identificação e Notificação dos Maus-tratos Infantis no Setor Educacional. Paidéia, Ribeirão Preto, v. 23, n. 54, p. 53-61, abr. 2013.

BRITO, Ana Maria M. Violência doméstica contra crianças e adolescentes: estudo de um programa de intervenção. Ciênc. saúde coletiva, Rio de Janeiro, v. 10, n. 1, p. 143-149, mar. 2005.

COSTA, Jurandir Freire. Ordem médica e norma familiar. 5. ed. Rio de Janeiro: Edições Graal, 2004.

DAVOLI, Adriana, et al. Prevalência de violência física relatada contra crianças em uma população de ambulatório pediátrico. Cad. Saúde Pública, Rio de Janeiro, v. 10, n. 1, p. 92-98, mar. 1994.

DESLANDES, Suely F. Atenção a crianças e adolescentes vítimas de violência doméstica: análise de um serviço. Cad. Saúde Pública, Rio de Janeiro, v. 10, supl. 1, p. 177-187, 1994.

DONOSO, Miguir Terezinha Vieccelli; RICAS, Janete. Perspectiva dos pais sobre educação e castigo físico. Rev. Saúde Pública, São Paulo, v. 43, n. 1, p. 78-84, fev. 2009.

EGRY, Emiko Yoshikawa, et al. Enfrentar a violência infantil na Atenção Básica: como os profissionais percebem? Rev. Bras. Enferm. Brasília, v. 70, n. 1, p. 119-125, fev. 2017.

EGRY, Emiko Yoshikawa; APOSTOLICO, Maíra Rosa; MORAIS, Tereza Christine Pereira. Notificação da violência infantil, fluxos de atenção e processo de trabalho dos profissionais da Atenção Primária em Saúde. Ciênc. saúde coleti- 
$v a$, Rio de Janeiro, v. 23, n. 1, p. 83-92, jan. 2018.

FONSECA, Rosa Maria Godoy Serpa, et al. Reincidência da violência contra crianças no Município de Curitiba: um olhar de gênero. Acta paul. enferm., São Paulo, v. 25, n. 6, p. 895-901, 2012.

FREITAS, Marcos Cezar de. História social da infância no Brasil. 6 ed. São Paulo: Cortez, 2006.

GOMES, Romeu, et al. Por que as crianças são maltratadas?: Explicações para a prática de maus-tratos infantis na literatura. Cad. Saúde Pública, Rio de Janeiro, v. 18, n. 3, p. 707-714, jun. 2002.

GOMES, Vera Lúcia de Oliveira; FONSECA, Adriana Dora da. Dimensões da violência contra crianças e adolescentes, apreendidas do discurso de professoras e cuidadoras. Texto contexto - enferm., Florianópolis, v. 14, número especial, p. 32-37, 2005.

GUERRA, Viviane Nogueira de Azevedo. Dez lições sobre a violência de pais contra filhos. Lua Nova, São Paulo, v. 3, n. 2, p. 38-45, dez. 1986.

LEITE, Miriam L. Moreira. A infância no século XIX segundo memórias e livros de viagem. In: FREITAS, Marcos Cezar (org.). História social da infância no Brasil. 6 ed. São Paulo: Cortez, 2006.

LEMOS, Flávia Cristina Silveira. O Estatuto da Criança e do Adolescente no Brasil atual. Rev. psicol. polít., São Paulo, v. 8, n. 15, p. 93-106, jun. 2008.

LIMA, Raymundo de. Lei da Palmada: algumas considerações. Revista Espaço Acadêmico, Maringá, vol. 11, n. 130, p. 95-100, 2012.

LONGO, Cristiano da Silveira. Ética disciplinar e punições corporais na infância. Psicol. USP, São Paulo, v.16, n.4, p. 99-119, 2005.

MARTINS, Christine Baccarat de Godoy. Maus tratos contra crianças e adolescentes. Rev. Bras. Enferm, Brasília, v.63, n.4, P. 660-665, jul./ago. 2010.

MARTINS, Christine Baccarat de Godoy; JORGE, Maria Helena Prado de Mello. Maus-tratos infantis: um resgate da história e das políticas de proteção. Acta paul. enferm., São Paulo, v. 23, n. 3, P. 417-422, jun. 2010.

MINAYO, Maria Cecília de Souza. Violência contra crianças e adolescentes: questão social, questão de saúde. Rev. Bras. Saúde Mater. Infant., Recife, v. 1, n. 2, p. 91-102, ago. 2001. 
MOREIRA, Gracyelle Alves Remigio et al. Fatores associados à notificação de maus-tratos em crianças e adolescentes na atenção básica. Ciênc. saúde coletiva, Rio de Janeiro, v. 19, n. 10, p. 4267-4276, out. 2014.

NUNES, Antonio Jakeulmo; SALES, Magda Coeli Vitorino. Violência contra crianças no cenário brasileiro. Ciênc. saúde coletiva, Rio de Janeiro, v. 21, n. 3, p. 871-880, mar. 2016.

OLIVEIRA, Denise Cristina de. Análise de conteúdo temático-categorial: uma proposta de sistematização. Revista enfermagem UERJ, Rio de Janeiro, v.16, n.4, p. 569-762, out./dez. 2008.

OLIVEIRA, Paula Sarreira de; SIMOES, Aida. Maus-tratos à infância: As referências dos técnicos das Comissões de Proteção de Crianças e Jovens [CPCJ]. Revista Portuguesa de Enfermagem de Saúde Mental, Porto, número especial, p. 82-89, abr. 2014.

PEREIRA, Paulo Celso; WILLIAMS, Lúcia Cavalcanti de Albuquerque. A concepção de educadores sobre violência doméstica e desempenho escolar. Psicol. Esc. Educ., Campinas, v. 12, n. 1, p. 139-152, jun. 2008.

PINTO JUNIOR, Antônio Augusto; CASSEPP-BORGES, Vicente; SANTOS, Janielly Gonçalves dos. Caracterização da violência doméstica contra crianças e adolescentes e as estratégias interventivas em um município do Estado do Rio de Janeiro, Brasil. Cad. saúde colet., Rio de Janeiro, v. 23, n. 2, p. 124-131, jun. 2015.

WEBER, Lidia Natalia Dobrianskyj; VIEZZER, Ana Paula; BRANDENBURG, Olivia Justen. $\mathrm{O}$ uso de palmadas e surras como prática educativa. Estud. Psicol., Natal, v. 9, n. 2, p. 227-237, ago. 2004.

Data de recebimento: 10.12 .2019

Data de aceite: 23.12 .2020 